\title{
Evaluation of the intranasal challenge route in mice as a mucosal model for Candida albicans infection
}

\author{
Patricia Londoño, ${ }^{1} \dagger$ Xiao M. Gao, ${ }^{1}$ Frances Bowe, ${ }^{1}$ William L. McPheat, ${ }^{2}$ \\ George Booth ${ }^{2}$ and Gordon Dougan'
}

Author for correspondence: Gordon Dougan. Tel: +44 171 5945256. Fax: +44 1715945255.

e-mail: g.dougan@ic.ac.uk

1 Biochemistry Department, Imperial College of

Science, Technology and Medicine, Exhibition Road, London SW7 2AY, UK

2 ZENECA Pharmaceuticals, Alderley Park Macclesfield, UK

\begin{abstract}
The intranasal route was used to study Candida albicans infections in mice. Mice from two different inbred strains were challenged intranasally with $C$. albicans and the level of local and systemic colonization was monitored. DBA/2 mice were highly susceptible to challenge and viable $C$. albicans disseminated from the lungs to deeper tissues, including kidneys, liver and spleen within $48 \mathrm{~h}$. In contrast, in BALB/c mice challenged in the same manner, $C$. albicans were retained within the lungs and cleared. Local and systemic anti-C. albicans immune responses were investigated. BALB/C mice exhibited higher titres of serum and mucosal anti-C. albicans IgA than DBA/2 mice. Splenocytes from BALB/c mice, but not from DBA/2 mice, produced detectable levels of interleukin-4 and -5 following stimulation with $C$. albicans antigens. Both DBA/2- and BALB/C-derived splenocytes produced interferon- $\gamma$ and interleukin10 in response to similar stimulation. In conclusion, the intranasal route provided a simple, non-invasive murine model for investigating $\mathrm{C}$. albicans infection through mucosal surfaces.
\end{abstract}

Keywords: Candida albicans, in vivo animal models, immunity, fungal infection, cytokines

\section{INTRODUCTION}

Candida albicans is frequently isolated from the commensal flora of healthy humans. However, C. albicans is also a significant cause of opportunistic infections and has emerged in recent years as a major cause of nosocomial infections (Pfaller, 1996). C. albicans infection in the immunocompromised host often involves colonization of vital organs such as the brain, liver and kidneys (Dupont, 1995; Klingspor et al., 1996). More common is the development of chronic mucosal candidiasis in the oropharyngeal or urinogenital tracts, particularly in HIV-infected patients (Klein et al., 1984; Samaranayake \& Holmstrop, 1989). Experimental approaches to investigating the immunology and pathogenicity of $C$. albicans have been substantially limited by the range of small animal models available for in vivo

†Present address: Peptide Therapeutics, 321 Cambridge Science Park, Cambridge, UK.

Abbreviations: ConA, Concanavalin A; HIY, heat-inactivated yeast cells; IFN, interferon; IL, interleukin; i.n., intranasal; i.v., intravenous. studies. The most frequently reported infection model utilizes intravenous (i.v.) challenge of inbred mice which can lead to a reproducible systemic infection with serious renal and cerebral compromise (Papadimitriou \& Ashman, 1986; Romani et al., 1993). Yet, clinical C. albicans infections most frequently develop from a mucosal site, with the gastrointestinal and urinogenital tracts serving as important $C$. albicans reservoirs. In rodents $C$. albicans has a limited ability to colonize the intestinal tract and to cause systemic disease after oral challenge. Significant colonization of the gastro-intestinal mucosa only occurs in adult immunocompetent mice if prolonged antibiotic treatment is given before and after C. albicans oral or intragastric challenge (Cenci et al., 1995; Greenfield \& Joyce, 1993; Helstrom $\&$ Balish, 1979). Germ-free mice orally infected with C. albicans may develop localized mucosal infections in the oro-intestinal tract (Jensen et al., 1996; Lacasse et al., 1993). However, intestinal infections resulting from oral challenge are usually self-limiting and do not spread to other organs, except if the mice are artificially immunosuppressed or exhibit severe genetic immunodeficiencies (Jensen et al., 1993, 1994; Samonis et al., 1994). 
Recently, the respiratory tract of mice has been explored as a mucosal challenge route using various enteric bacterial pathogens. For example, the human pathogens Shigella flexneri and Shigella sonnei are unable to infect mice when inoculated orally, but when administered to the respiratory tract they invade the murine pulmonary epithelia, evoking a pathology which shows some resemblance to the colitis which characterizes intestinal shigellosis in humans (Mallett et al., 1995, 1993; van de Verg et al., 1995; Voino-Yasenetsky \& VoinoYasenetsky, 1962). This model has been exploited to study the immunobiology of shigellosis and to evaluate potential vaccines (Barzu et al., 1996; Noriega et al., 1996; Phalipon et al., 1995; Sizemore et al., 1997). There is evidence from calves and pigs that the upper respiratory tract is also a susceptible site for Salmonella invasion. Salmonella dublin and Salmonella typhimurium can spread systemically to organs such as the liver, spleen and intestines upon challenge through the upper respiratory tract (Fedorka-Cray et al., 1995; Gray et al., 1995; Roof \& Doitchinoff, 1995; Stabel et al., 1995). Salmonella typhi, a highly host-restricted human intestinal pathogen, is incapable of inducing a progressive systemic disease in mice following oral inoculation. However, when delivered intranasally, $S$. typhi can elicit strong systemic and mucosal immune responses which can be used to predict the behaviour of the strain in human oral inoculation trials (Barry et al., 1996; Galen et al., 1997).

Challenge through the respiratory tract and intranasal (i.n.) challenge in particular, has not been explored in experimental models of $C$. albicans infection as extensively as oro-gastric challenge. Intratracheal deposition has been used to infect mice (Hurley, 1966; Nuget \& Onofrio, 1983; Sawyer, 1990) and concomitant systemic spread was only observed if mice were treated with steroids after challenge (Hurley, 1966; Nuget \& Onofrio, 1983). Similarly, i.n. challenge has been reported to result in systemic dissemination in mice rendered neutropenic by cyclophosphamide treatment (Fallon et al., 1997). In this study we have shown that, following i.n. infection of immunocompetent adult mice, C. albicans can elicit an inflammatory response in the lungs and subsequently disseminate to kidneys, liver and spleen in a susceptible (DBA/2) but not in a resistant $(B A L B / c)$ mouse strain. We have analysed the antiC. albicans immune responses elicited by i.n. challenge in these mice and have described the differences found in mucosal and systemic antibody and cellular responses. We propose that the model described here could be used to investigate the process of systemic C. albicans spread from mucosal surfaces and the role of mucosal immune responses in candidiasis.

\section{METHODS}

Growth and characterization of C. albicans. A well characterized, clinical serotype A isolate of C. albicans, named MG3, was used throughout this study (characterization carried out in Dr David Coleman's laboratory, Department of Microbiology, Trinity College, Dublin). This strain is germ-tube- positive and chlamydospore-positive and yields the chlamydospore presentation profile typical of $C$. albicans. It yields bluegreen colonies on Chromagar Candida medium, grows well at 30,37 and $42^{\circ} \mathrm{C}$ and its carbohydrate assimilation profile is characteristic of $C$. albicans. MG3 has DNA fingerprint characteristics typical of C. albicans serotype A, has the ability to germinate in the presence of bovine serum and is resistant to cycloheximide. The strain was routinely maintained in Potato Dextrose agar (PDA; Difco). Stocks of live yeast to be used for animal infections were prepared from 18-h-old cultures of $C$. albicans MG3 in Sabouraud broth (Difco) at $37^{\circ} \mathrm{C}$ (cell density of at least $1 \times 10^{8}$ c.f.u. $\mathrm{ml}^{-1}$ ). Yeast cells were harvested by centrifugation at $800 \mathrm{~g}$ for $10 \mathrm{~min}$. After three washes with endotoxin-free PBS (Sigma), yeast cells were resuspended in approximately $0 \cdot 2$ vols endotoxin-free PBS, aliquoted, snap-frozen and stored at $-70^{\circ} \mathrm{C}$. Aliquots were thawed immediately before inoculation and their concentration adjusted to $3 \times 10^{8}-4 \times 10^{8}$ c.f.u. $\mathrm{ml}^{-1}$. To confirm stock viability and enumerate viable yeast cells, aliquots of different dilutions of thawed stocks were plated on PDA. Colonies were enumerated (c.f.u.) after 24-36 h incubation at $37^{\circ} \mathrm{C}$. No significant decrease in the viability of stocks was observed over storage periods longer than 6 months.

i.n. and i.v. infection of mice and enumeration of viable $C$. albicans in mouse organs. BALB/c and DBA $/ 2$ mice were purchased from Harlem. Mice of the same sex and age (8-12 weeks old) were used for all the experiments. For i.n. infections, mice were anaesthetized with halothene and, unless otherwise stated, $30 \mu \mathrm{lPS}$ containing $1 \times 10^{7}$ live yeast cells was very slowly dropped over their nares using a Gilson Pipetman. For i.v. infections, $100 \mu \mathrm{l}$ PBS containing $10^{3}-10^{5}$ yeast cells were injected into a tail vein. The animals were maintained under observation and those showing symptoms of distress were sacrificed by cervical dislocation, a standard method for humane culling of small rodents listed in the UK Animals (Scientific Procedures) Act 1986. To follow the course of infection, groups of four challenged mice were sacrificed on different days after infection. For enumeration of C. albicans in mouse organs, lungs, liver, spleen and kidneys were removed and homogenized using a glass homogenizer (lungs) or a Stomacher (other organs). Viable C. albicans were counted by plating different dilutions of the homogenates on PDA, as described above. For assessment of $\mathrm{LD}_{50}$, groups of 6 mice were infected either intranasally or intravenously with maximum doses of $3 \times 10^{7}$ or $1 \times 10^{6}$ live yeast cells, respectively. Mice were kept under observation for 45 (i.n. challenge) or 52 (i.v. challenge) d and deaths were recorded on a daily basis. The Reed-Muench method was used to calculate $\mathrm{LD}_{50}$ (Welkos \& O'Brien, 1994).

Histology. Lungs from mice infected $4 \mathrm{~h}$ previously with $1 \times 10^{7}$ yeast cells were fixed in $10 \%(\mathrm{v} / \mathrm{v})$ neutral buffered formalin, embedded in paraffin wax and sectioned. Sections were either stained with hematoxylin and eosin or immunostained using the Vectastain ABC Reagent (Anti-Rabbit IgG Kit; Vector Laboratories). The primary antiserum used was a commercial rabbit polyclonal antiserum against $C$. albicans diluted 1/400 (Dako). Endogenous peroxidase was blocked for 3 min with $0 \cdot 3 \% \mathrm{H}_{2} \mathrm{O}_{2}$ in methanol. Counter staining was performed with Mayer's Haemalum.

Cell proliferation and cytokine assays. Naive or C. albicansinfected mice were splenectomized on different days after challenge. Single cell suspensions from pooled spleens of 3-4 mice per group were prepared in DMEM supplemented with $5 \%(\mathrm{v} / \mathrm{v})$ heat-inactivated foetal bovine serum, $2 \mathrm{mM} \mathrm{L-}$ 
glutamine, $50 \mathrm{mM}$ 2-mercaptoethanol and $10 \mathrm{mM}$ HEPES (all from Sigma). Aliquots $(200 \mu \mathrm{l})$ of $4 \times 10^{5}$ splenocytes were stimulated with different numbers of heat-inactivated yeast cells (HIY), killed by incubation at $60^{\circ} \mathrm{C}$ for $2 \mathrm{~h}$. Controls included cells stimulated with either medium or Concanavalin A (ConA; Sigma). Cellular proliferation was measured by incorporation of $\left[{ }^{3} \mathrm{H}\right]$ thymidine (Amersham) during the last $18-20 \mathrm{~h}$ of $96-\mathrm{h}$-old cultures. For cytokine analysis, $1 \mathrm{ml}$ aliquots of $2 \times 10^{6}$ splenocytes were cultured with HIY $\left(1.2 \times 10^{6}\right.$ yeast cells $\left.\mathrm{ml}^{-1}\right)$, medium only or ConA $(2.5 \mu \mathrm{g}$ $\left.\mathrm{ml}^{-1}\right)$. Supernatants from quadruplicate samples were collected at various times after stimulation and stored at $-70^{\circ} \mathrm{C}$. For quantification of interferon- $\gamma$ (IFN $\gamma$ ), interleukin-10 (IL10), IL4 and IL5 in culture supernatants, commercial ELISA systems were used (Pharmingen). Limits of detection for

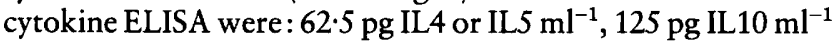
and $312 \mathrm{pg}$ IFN $\gamma \mathrm{ml}^{-1}$.

Antibody responses. Sera from groups of 3-4 mice, obtained on different days of $C$. albicans infection, were pooled for titration. Levels of specific anti-C. albicans antibodies were measured by ELISA. Nunc maxisorb plates were coated with a sonicate extract of live C. albicans MG3 yeast cells $(30 \mu \mathrm{g}$ $\mathrm{ml}^{-1}$ in sodium carbonate buffer, $\mathrm{pH}$ 9.6). Serum samples were used in duplicates from a 1:50 dilution. Biotinylated antimouse IgG, IgA (Sigma) or IgG1, IgG2a, IgG2b or IgG3 (Pharmingen) were used as secondary antibodies. These were detected with a streptavidin-horseradish peroxidase conjugate (Dako). Titres were defined as the lowest dilution of sera to give an $A_{492}$ above the mean $A_{492}$ of naive sera $+2 \times$ SEM.

Specific anti-C. albicans IgA was measured in lung lavages from groups of 4-6 mice obtained as described previously (Douce et al., 1995). To compare the levels of specific anti-C. albicans $\operatorname{IgA}$ in the lavages, titres were expressed as ELISA units (EU) ( $\mu$ g total $\operatorname{IgA})^{-1}$, thus preventing errors due to differences in total content of IgA. The total content of IgA present on pooled lavage samples was assessed in a sandwich ELISA using plates coated with anti-mouse IgA antibody as described by Elson et al. (1984). The content of specific anti-C. albicans IgA on lavages was measured using the same ELISA as for serum antibodies. The number of EU present on the lavages was established by comparison to a reference mouse serum that contained a high titre of anti-C. albicans IgA antibodies, to which an arbitrary concentration $\left(\mathrm{EU} \mathrm{ml} \mathrm{l}^{-1}\right)$ was assigned.

\section{RESULTS}

\section{Susceptibility of BALB/C and DBA/2 mice to C. albicans MG3 i.n. challenge}

C. albicans MG3 challenge through either the i.v. or i.n. routes showed that $\mathrm{BALB} / \mathrm{c}$ mice were more resistant to C. albicans MG3 infection than DBA/2 mice (Table 1). The i.v. data, included as control, agree with previously published observations (Ashman et al., 1993; Hector et al., 1982; Romani et al., 1993). All DBA/2 mice intravenously challenged with a dose of $10^{5}$ yeast cells succumbed to the infection, whereas more than $50 \%$ of the BALB/c mice survived a similar challenge. The i.v. $\mathrm{LD}_{50}$ for $\mathrm{BALB} / \mathrm{c}$ mice was at least four times greater than for DBA / 2 mice (Table 1 ). Intranasally challenged $\mathrm{BALB} / \mathrm{c}$ mice could survive a dose of $3 \times 10^{7}$ yeast cells, whereas more than half of the DBA $/ 2$ mice succumbed to the same challenge. The i.n. $L_{50}$ for $B A L B / c$ mice was at least two times higher than for $\mathrm{DBA} / 2$ mice
Table 1. Survival of $B A L B / C$ and $D B A / 2$ mice upon C. albicans challenge

The table shows the number of surviving mice at the end of the observation period/total number of mice challenged. Mice were kept under observation for 45 (i.n. challenge) or 52 (i.v. challenge) $d$.

\begin{tabular}{|ccc|}
\hline Dose $^{*}$ & BALB/c & DBA/2 \\
\hline i.v. challenge & & \\
$1 \times 10^{5}$ & $4 / 6$ & $0 / 6$ \\
$1 \times 10^{4}$ & $5 / 6$ & $5 / 6$ \\
$1 \times 10^{3}$ & $6 / 6$ & $6 / 6$ \\
LD $_{50}$ & $>1.3 \times 10^{5}$ & $2.5 \times 10^{4}$ \\
i.n. challenge & & \\
$3 \times 10^{7}$ & $6 / 6$ & $2 / 6$ \\
$1 \times 10^{7}$ & $6 / 6$ & $6 / 6$ \\
$3 \times 10^{6}$ & $6 / 6$ & $6 / 6$ \\
$\mathrm{LD}_{50}$ & $>5.1 \times 10^{7}$ & $2.3 \times 10^{7}$ \\
\hline
\end{tabular}

* C. albicans MG3 c.f.u. per mouse.

(Table 1). Examination of dead DBA/2 mice after i.n. challenge showed heavy $C$. albicans MG3 loads in the kidneys, comparable to those observed after i.v. infection (data not shown). BALB/c mice that died following i.v. challenge also showed heavy $C$. albicans loads on their kidneys ( $>1 \times 10^{4}$ c.f.u. per organ).

\section{Kinetics of infection after i.n. challenge}

Following i.n. challenge with $1 \times 10^{7}$ live yeast cells, viable $C$. albicans MG3 were recovered from the lungs of BALB/c and DBA/ 2 mice at different time points (Fig. 1). The course of lung infection was very similar in both mouse strains during the first $48 \mathrm{~h}$ after challenge. However, by day 5 the C. albicans load in the lungs of DBA/2 mice was significantly higher (approx. 50-fold higher) than that of BALB $/ \mathrm{c}$ mice $(P<0.05$, as calculated by Student's $t$ test). By day 7, no significant difference was observed in the number of C. albicans recovered from the lungs of both strains of mice.

BALB/c mice were not only able to clear C. albicans from their lungs more rapidly, but they could also avoid significant $C$. albicans spread to other organs such as kidneys, liver (Table 2, Fig. 1) and spleen (Table 2). In contrast, the majority of DBA/2 mice exhibited significant colonization of one or more of these organs (Table 2). C. albicans colonization of the kidneys and liver peaked between 2 and $5 \mathrm{~d}$ after challenge (Fig. 1). A positive correlation was found between the C. albicans load in the lungs and that of kidneys or liver (data not shown).

\section{Histopathology of C. albicans infection in the lung}

The lungs of mice were examined after i.n. challenge to determine the early fate of C. albicans MG3 cells within host tissues. At $4 \mathrm{~h}$ after challenge there were detectable 

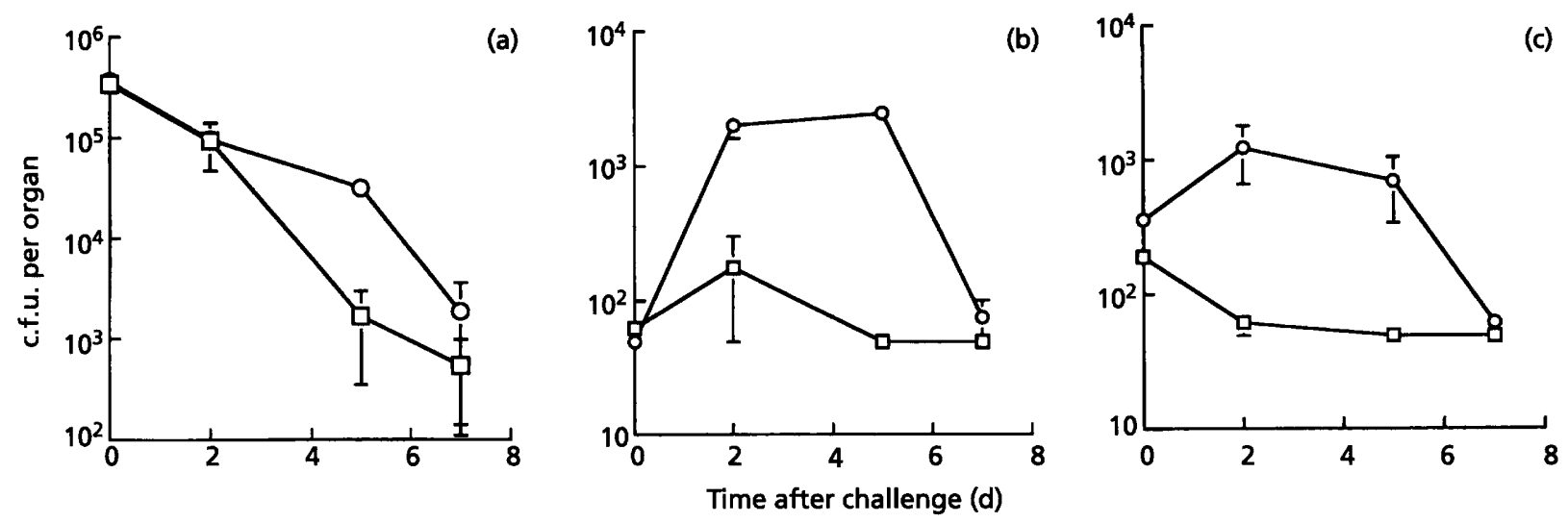

Fig. 1. Course of $C$. albicans infection in the lungs (a), kidneys (b) and liver (c) of intranasally challenged BALB/c ( $\square$ ) and $D B A / 2(O)$ mice. Mice were challenged with $1 \times 10^{7}$ live yeast cells. The results shown correspond to the mean \pm SEM of two experiments. For each experiment, 4 animals were sacrificed per time point. Counts shown for day 0 were obtained $4 \mathrm{~h}$ after challenge. Limits of detection were 20 c.f.u. per organ in lungs and 50 c.f.u. per organ in liver and kidneys.

Table 2. Systemic dissemination of $C$. albicans after i.n. challenge

The table shows the number of organs from which viable $C$. albicans were recovered/total number of organs examined. The limit of detection was 50 c.f.u. per organ. Results shown were obtained with groups of 8 or 9 mice per strain sacrificed 2 or $5 \mathrm{~d}$ after challenge.

\begin{tabular}{|lcccc|}
\hline Mouse strain & Kidneys & Liver & Spleen & Total $^{*}$ \\
\hline BALB/c & $1 / 16$ & $3 / 16$ & $1 / 16$ & $3 / 16$ \\
DBA $/ 2$ & $7 / 17$ & $9 / 17$ & $7 / 17$ & $10 / 17$ \\
\hline
\end{tabular}

* Number of mice from which viable yeast cells were recovered from one or more of the organs shown per total number of mice examined.

C. albicans MG3 adjacent to the respiratory bronchioles in the lungs of both $\mathrm{BALB} / \mathrm{c}$ and $\mathrm{DBA} / 2$ mice. No discernible differences in the histology of lungs prepared from C. albicans MG3-infected DBA/2 or BALB/c mice were found at this stage of the infection. C. albicans MG3 in hyphal and yeast forms were visible in airways and also in surrounding tissue by immunostaining with a C. albicans-specific rabbit serum and hematoxylin and eosin. An inflammatory infiltrate, composed of polymorphonuclear lymphocytes and mononuclear cells, was also detectable in sections from both mouse strains (data not shown).

\section{Cellular response against $C$. albicans MG3 upon i.n. challenge}

Anti-C. albicans cellular responses, as determined in splenocyte proliferation assays, were detected in both $\mathrm{DBA} / 2$ and $\mathrm{BALB} / \mathrm{c}$ mice from $7 \mathrm{~d}$ after i.n. challenge. The response peaked on day 7 in BALB/c mice and on day 14 in DBA/2 mice and remained detectable for at least $50 \mathrm{~d}$ after challenge in both strains of mice (data not shown). The profiles of cytokine secretion by the proliferating splenocytes showed differences (Fig. 2). While both splenocyte populations produced IFN $\gamma$ and IL10, production of IL4 and IL5 was only detected in $\mathrm{BALB} / \mathrm{c}$, but not DBA/2, splenocytes. Similar results were obtained with splenocytes harvested 7, 14 (Fig. 2) or $21 \mathrm{~d}$ (data not shown) after challenge. As expected, all the cytokines measured were secreted by DBA $/ 2$ and BALB/c splenocyte populations in response to ConA stimulation (data not shown).

\section{Antibody response to C. albicans MG3}

Humoral responses against C. albicans MG3 were detected in both BALB/c and DBA/ 2 mice following $C$. albicans MG3 i.n. challenge. A significant anti-C. albicans IgG response appeared earlier in DBA/2 mice (day 7) than in BALB/c mice (day 14) (Fig. 3). The antibody response did not significantly change over a period of $90 \mathrm{~d}$ (data not shown). IgG1, IgG2a, IgG2b and IgG3 antibody subclasses contributed to the anti-C. albicans response in $\mathrm{BALB} / \mathrm{c}$ mice, although $\operatorname{IgG} 2 \mathrm{a}$ appeared to be slightly dominant. In contrast, in DBA/2 mice, IgG2b was clearly the predominant IgG subclass and anti-C. albicans IgG1 was not detected.

Following i.n. challenge, BALB/c, but not DBA/2 mice exhibited a systemic IgA response against $C$. albicans MG3 (Fig. 3). The titre of the response in BALB/c mice was higher on day 14 than on day 7 . The local production of IgA paralleled the systemic response (Table 3). Specific anti-C. albicans IgA was detected in lung lavages of $B A L B / c$, but not DBA/ 2 mice after primary i.n. infection. However, this pattern of local IgA production changed after a secondary i.n. infection with C. albicans MG3 as anti-C. albicans IgA was found in lung lavages of both strains of mice (Table 3). 

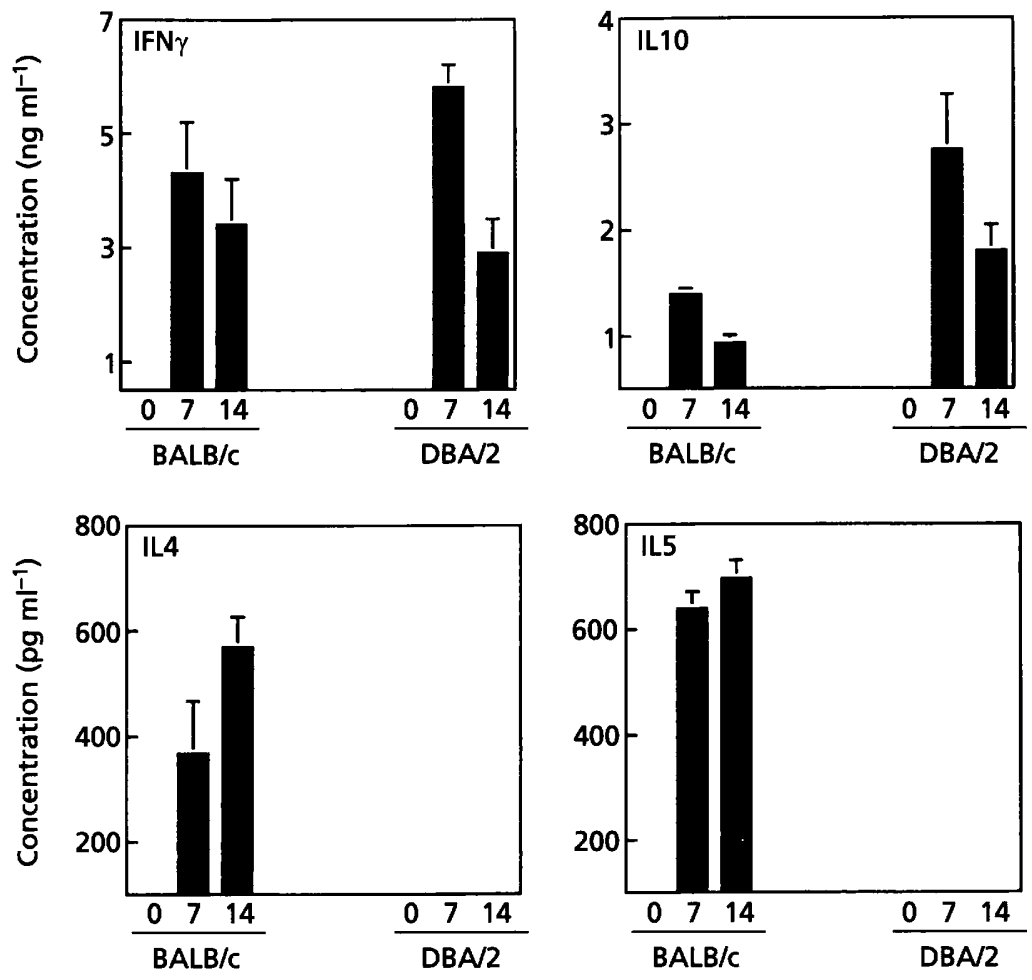

\begin{abstract}
Fig. 2. Cytokine production by splenocytes from C. albicans-infected mice. Splenocytes were obtained from mice before and 7 or $14 \mathrm{~d}$ after i.n. challenge with $1 \times 10^{7}$ live yeast cells. Concentrations of IL4, IL5, IL10 and IFN $\gamma$ shown were measured in supernatants of splenocytes stimulated with $1.2 \times 10^{6}$ HIY for 72 (IL10 and IFN $\gamma$ ) or 96 (IL4 and IL5) $\mathrm{h}$. Experiments were performed two (BALB/C mice) or three (DBA/2 mice) times with similar results. Splenocytes cultured in medium only did not produce detectable amounts of any of the cytokines measured.
\end{abstract}

\section{DISCUSSION}

In this study we have shown that i.n. administration of C. albicans to adult immunocompetent mice may be used as a model to study the pathogenesis and immunobiology of C. albicans infection. Both local and systemic immune responses can be evaluated after i.n. challenge, thus potentially allowing an analysis of the contribution of both of these arms of the immune response to protection against $C$. albicans infection originated from mucosal surfaces. DBA $/ 2$ mice $\left(\mathrm{H}-2^{\mathrm{d}}\right)$ have been shown previously to be more susceptible to i.v. C. albicans challenge than BALB/c mice (also $\mathrm{H}-2^{\mathrm{d}}$ ) (Ashman et al., 1993; Hector et al., 1982; Romani et al., 1993). This pattern of susceptibility was also apparent following i.n. challenge. $\mathrm{BALB} / \mathrm{c}$ mice survived i.n. challenge with $3 \times 10^{6}-3 \times 10^{7}$ live yeast cells, while $\mathrm{DBA} / 2$ mice succumbed to a similar challenge in a dose-dependent manner. Interestingly, the C. albicans loads observed in the kidneys of dead DBA/2 mice after i.n. challenge resembled those detected in mice that succumbed to lethal i.v. challenge $\left(>1 \times 10^{4}\right.$ c.f.u. per organ). In addition, DBA/2, but not BALB/c mice, also succumbed to i.n. challenge with four other $C$. albicans isolates, although C. albicans MG3, the isolate used in this study, exhibited the highest relative virulence (data not shown).

The course of $C$. albicans infection in intranasally challenged $\mathrm{BALB} / \mathrm{c}$ and $\mathrm{DBA} / 2$ mice was also considerably different. In $\mathrm{BALB} / \mathrm{c}$ mice $C$. albicans were cleared steadily from the lungs with no significant systemic spreading of the infection. In DBA / 2 mice there was a delay in the initiation of C. albicans clearance from the lung and systemic C. albicans colonization was evident (Fig. 1 and Table 2). Significant numbers of live C. albicans were recovered from the kidneys, spleen and liver of DBA/2 mice (Table 2). In particular, after i.n. challenge, only DBA $/ 2$ mice exhibited C. albicans loads in their kidneys at levels comparable to those observed after i.v. challenge (data not shown).

In this study a significant infiltrate of both mononuclear cells and neutrophils was observed in the lungs of both BALB/c and DBA/2 mice after C. albicans i.n. challenge (data not shown). Nuget \& Onofrio (1983) have reported that in Swiss Webster mice, pulmonary macrophages, together with infiltrating neutrophils, provide the first line of protection against intratracheal challenge with live C. albicans yeast cells. More recently, Fallon $e t$ al. (1997) found that neutropenic Swiss Webster mice are highly susceptible to $C$. albicans i.n. challenge. Infiltration and accumulation of inflammatory cells, especially mononuclear cells and neutrophils, have also been observed in the gastro-intestinal mucosa of gastrically challenged $\mathrm{BALB} / \mathrm{c}$ and $\mathrm{DBA} / 2$ mice rendered susceptible to transient $C$. albicans colonization by prolonged antibiotic treatment. However, in this case both $\mathrm{BALB} / \mathrm{c}$ and DBA $/ 2$ mice eventually cleared the local gastro-intestinal infection in the absence of systemic colonization (Bistoni et al., 1993; Cenci et al., 1995). Although comparable early inflammatory responses were elicited by i.n. C. albicans challenge in the lungs of $\mathrm{BALB} / \mathrm{c}$ and $\mathrm{DBA} / 2$ mice, differences were observed between these murine strains in the rate of $C$. albicans clearance from the lungs after $48 \mathrm{~h}$ of challenge. In DBA/ 2 mice the delay in C. albicans clearance could have resulted from either the temporary establishment of a balance between C. albicans killing and C. albicans 


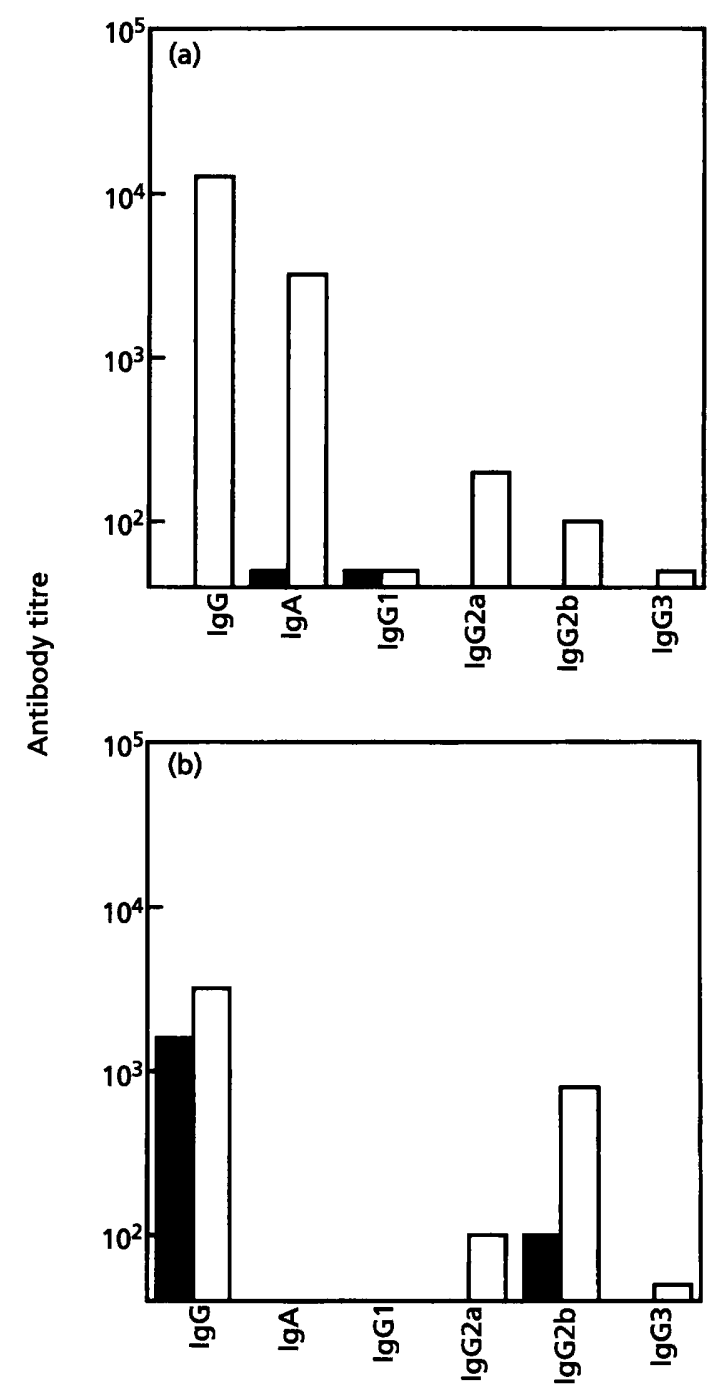

Fig. 3. Serum antibody levels against $C$. albicans in BALB/C (a) and $\mathrm{DBA} / 2$ (b) mice challenged intranasally with live yeast cells. Antibody titres were determined in sera obtained $7(\square)$ and 14 ( $\square$ ) $d$ after challenge, as described in Methods. Values shown represent the titre of pooled sera from 3-4 mice per group. Titres beneath $1 / 50$ were below detection limits of the assay. SEM was below $5 \%$.

growth or from the discrete activation of a candidastatic rather than candidacidal immune mechanism. This mechanism was probably systemic rather than local to the lungs since colonization occurred in various organs simultaneously. DBA/2 mice are known to lack the complement molecule $\mathrm{C} 5$. Although this deficiency has been eliminated as a factor associated with their increased susceptibility to acute i.v. challenge (Sawyer, 1990; Ashman et al., 1991), it may still play a role during mucosal infections.

Resistance to i.v. C. albicans challenge in $\mathrm{BALB} / \mathrm{c}$ mice is accompanied by a Th1 cellular response, while susceptibility of DBA/2 mice is associated with development of a Th2 response (Romani et al., 1995).
Table 3. Specific anti-C. albicans IgA response in lung lavages of intranasally challenged mice

Lung lavages were carried out in groups of $4-6$ mice sacrificed $15 \mathrm{~d}$ after primary or $21 \mathrm{~d}$ after secondary i.n. C. albicans challenge. Values shown were calculated as described in Methods and represent the titre of pooled lavages obtained from each particular group of mice. SEM was below $5 \%$. ND, Not detected.

\begin{tabular}{|lcc|}
\hline Infection & \multicolumn{2}{c|}{ Titre $\left[\right.$ EU $\left.(\mu \mathrm{g} \text { total IgA })^{-1}\right]$} \\
\cline { 2 - 3 } & BALB/c & DBA $/ 2$ \\
\hline Primary & 1.67 & ND \\
Secondary & 9.35 & 18.91 \\
\hline
\end{tabular}

Intragastrically challenged $\mathrm{DBA} / 2$ and $\mathrm{BALB} / \mathrm{c}$ mice develop Th1 and a combination of Th1 and Th2 anti-C. albicans responses, respectively (Bistoni et al., 1993; Cenci et al., 1995). Challenge of mice by topical application of C. albicans in the oral mucosa generates detectable T-cell responses in DBA/2 but not BALB/c mice (Chakir et al., 1994). In this study significant differences were found in the pattern of cytokine expression by $C$. albicans-activated splenocytes from intranasally infected $\mathrm{BALB} / \mathrm{c}$ and $\mathrm{DBA} / 2$ mice. The cellular responses observed resemble those reported in the same mice upon intragastric $C$. albicans challenge (Bistoni et al., 1993; Cenci et al., 1995). As a result of i.n. challenge, C. albicans-dependent IL4 and IL5 secretion was only detected in BALB/c splenocyte cultures, while C. albicans-dependent IL10 and IFN $\gamma$ secretion was detected in both BALB/c and DBA/2 splenocyte populations. The differences in cytokine response correlated with the anti-C. albicans antibody response of these mice. The presence of specific mucosal and serum $\operatorname{IgA}$ as well as IgG1 responses in BALB/c, but not in DBA/2 mice could be attributed to the synthesis of IL5 and IL4 by BALB/c-, but not DBA/2-activated lymphocytes. Furthermore, the production of IgG3 and IgG2a in both mouse strains may be linked to the presence of comparable IFN $\gamma$ responses (Abbas et al., 1996). The animal model of i.n. C. albicans infection described here could be explored further to determine the effect of mucosal antibody responses during C. albicans infection. Significantly, in this study resistant BALB/c, but not susceptible DBA/2 mice exhibited detectable levels of local mucosal and also humoral $\operatorname{IgA}$ against $C$. albicans after primary i.n. challenge. Interestingly, DBA/ 2 mice also exhibit defective production of IgA after intragastric, but not i.v. C. albicans challenge (Bistoni et al., 1993; Cenci et al., 1995).

In summary, the data presented here indicate the following. (i) Lethal systemic candidiasis may be induced in healthy adult mice by i.n. C. albicans challenge with no requirement for artificial immunosuppression or antibiotic treatment. (ii) i.n. C. albicans challenge results in transient lung colonization of both $\mathrm{DBA} / 2$ and 
$\mathrm{BALB} / \mathrm{c}$ mice; however, only in DBA/2 mice is this accompanied by systemic spreading of the organism. (iii) i.n. C. albicans challenge elicits cellular immune responses in $\mathrm{DBA} / 2$ and $\mathrm{BALB} / \mathrm{c}$ mice which resemble their respective responses to intragastric rather than i.v. challenge. (iv) After primary i.n. C. albicans infection, systemic and local anti-C. albicans $\operatorname{IgA}$ responses are detected in mice that rapidly clear the organism from their lungs $(\mathrm{BALB} / \mathrm{c})$, but not in those in which systemic spreading occurs (DBA/2).

The i.n. model of C. albicans infection is not based on clinical observations. Pulmonary candidiasis is a very rare occurrence in clinical practice. In humans systemic C. albicans infections are believed to originate in the intestinal rather that the respiratory tract. Nevertheless, the i.n. challenge model mirrors the early stage of this process, i.e. dissemination of the yeast from a mucosal surface. This process is by-passed by the most commonly used i.v. challenge model and cannot be reproduced in normal adult mice by oral challenge. The advantages of using an i.n. model of C. albicans infection have been highlighted recently (Fallon et al., 1997). This model will be very valuable in studying the generation of systemic, and especially mucosal, immune responses during $C$. albicans colonization of mucosal surfaces as well as their contribution to prevention of systemic dissemination of infection.

\section{ACKNOWLEDGEMENTS}

This paper is dedicated to the memory of D.A. who very sadly died during cancer treatment suffering the dreadful consequences of our ignorance about C. albicans. We are grateful to Dr David Coleman at Trinity College, Dublin, for his help with the characterization of the clinical C. albicans isolate used in this study. We would like to thank Dr Gill Douce and Dr Paul Everest for very helpful technical advice and discussions. Also, the staff at the CBS unit at Imperial College for technical assistance. This work was supported by ZENECA Pharmaceuticals.

\section{REFERENCES}

Abbas, A. K., Murphy, K. M. \& Sher, A. (1996). Functional diversity of helper T-lymphocytes. Nature 383, 787-793.

Ashman, R. B., Kay, P. H., Lynch, D. M. \& Papadimitriou, J. M. (1991). Murine candidiasis : sex differences in the severity of tissue lesions are not associated with levels of $\mathrm{C} 3$ and C5. Immunol Cell Biol 69, 7-10.

Ashman, R. B., Bolitho, E. M. \& Papadimitriou, J. M. (1993). Patterns of resistance to Candida albicans in inbred mouse strains. Immunol Cell Biol 71, 221-225.

Barry, E. M., Gomez-Duarte, O., Chatfield, S., Rappuoli, R., Pizza, M., Losonsky, G., Galen, J. \& Levine, M. M. (1996). Expression and immunogenicity of pertussis toxin $S 1$ subunit-tetanus toxin fragment C fusion in Salmonella typhi vaccine strain CVD908. Infect Immun 64, 4172-4181.

Barzu, S., Fontaine, A., Sansonetti, P. \& Phalipou, A. (1996). Induction of a local anti-Ipa $C$ antibody response in mice by use of a Shigella flexneri 2 a vaccine candidate: implications for use of IpaC as a protein carrier. Infect Immun 64, 1190-1196.

Bistoni, F., Cenci, E., Mencacci, A., Schiaffella, E., Mosci, P.,
Puccetti, P. \& Romani, L. (1993). Mucosal and systemic T helper cell function after intragastric colonization of adult mice with Candida albicans. J Infect Dis 168, 1449-1457.

Cenci, E., Mencacci, A., Spaccapelo, R., Tonnetti, L., Mosci, P., Enssle, K. H., Puccetti, P., Romani, L. \& Bistoni, F. (1995). T helper cell type 1 (Th1)- and Th2-like responses are present in mice with gastric candidiasis but protective immunity is associated with Th1 development. J Infect Dis 171, 1279-1288.

Chakir, J., Cote, L., Coulombe, C. \& Deslauriers, N. (1994). Differential pattern of infection and immune response during experimental oral candidiasis in $\mathrm{BALB} / \mathrm{c}$ and $\mathrm{DBA} / 2(\mathrm{H}-2 \mathrm{~d})$ mice. Oral Microbiol Immunol 9, 88-94.

Douce, G., Turcotte, C., Cropley, I., Roberts, M., Pizza, M., Domenghini, M., Rappuoli, R. \& Dougan, G. (1995). Mutants of $E$. coli heat-labile toxin lacking ADP-ribosyltransferase activity act as nontoxic mucosal adjuvants. Proc Natl Acad Sci USA 92, 1644-1648.

Dupont, P. F. (1995). Candida albicans, the opportunist. A cellular and molecular perspective. J Am Podiatr Med Assoc 85, 104-115.

Elson, C. O., Ealding, W. \& Lefkowitz, J. (1984). A lavage technique allowing repeated measurement of $\operatorname{IgA}$ antibody in mouse intestinal secretions. J Immunol Methods 67, 101-108.

Fallon, K., Bausch, K., Noonan, J., Huguenel, E. \& Tamburini, P. (1997). Role of aspartic proteases in disseminated Candida albicans infection in mice. Infect Immun 65, 551-556.

Fedorka-Cray, P. J., Kelley, L. C., Stabel, T. J., Gray, J. T. \& Laufer, J. A. (1995). Alternate routes of invasion may affect pathogenesis of Salmonella typhimurium in swine. Infect Immun 63, 26582664.

Galen, J. E., Gomez-Duarte, O. G., Losonsky, G. A., Halpern, J. L., Lauderbaugh, C. S., Kaintuck, S., Reymann, M. K. \& Levine, M. M. (1997). A murine model of intranasal immunisation to assess the immunogenicity of attenuated Salmonella typhi live vector vaccines in stimulating serum antibody responses to expressed foreign antigens. Vaccine 15, 700-708.

Gray, J. T., Fedorka-Cray, P. J., Stabel, T. J. \& Ackermann, M. R. (1995). Influence of inoculation route on the carrier state of Salmonella choleraesuis in swine. Vet Microbiol 47, 43-59.

Greenfield, R. A. \& Joyce, W. A. (1993). Gastric colonization with Candida albicans. Mycopathologia 122, 1-5.

Hector, R. F., Domer, J. E. \& Carrow, E. W. (1982). Immune responses to Candida albicans in genetically distinct mice. Infect Immun 38, 1020-1028.

Helstrom, P. B. \& Balish, E. (1979). Effect of oral tetracycline, the microbial flora, and the athymic state on gastrointestinal colonization and infection of BALB/c mice with Candida albicans. Infect Immun 23, 764-774.

Hurley, R. (1966). Effect of route of entry of Candida albicans on the histogenesis of the lesions in experimental candidosis in the mouse. J Pathol Bacteriol 92, 578-583.

Jensen, J., Warner, T. \& Balish, E. (1993). Resistance of SCID mice to Candida albicans administered intravenously or colonizing the gut: role of polymorphonuclear leukocytes and macrophages. $J$ Infect Dis 167, 912-919.

Jensen, J., Warner, T. \& Balish, E. (1994). The role of phagocytic cells in resistance to disseminated candidiasis in granulocytopenic mice. J Infect Dis 170, 900-905.

Jensen, J., Warner, T., Johnson, C. \& Balish, E. (1996). Oral immunization of mice against candidiasis. J Infect Dis 174, 133-140.

Klein, R. S., Harris, C. A., Small, C. B., Moll, B., Lesser, M. \& Friedland, G. H. (1984). Oral candidiasis in high risk patients as 
the initial manifestation of the acquired immunodeficiency syndrome. $N$ Engl J Med 311, 354-358.

Klingspor, L., Stintzing, G., Fasth, A. \& Tollemar, J. (1996). Deep Candida infection in children receiving allogeneic bone marrow transplants: incidence, risk factors and diagnosis. Bone Marrow Transplant 17, 1043-1049.

Lacasse, M., Fortier, C., Chakir, J., Cote, L. \& Deslauriers, N. (1993). Acquired resistance and persistence of Candida albicans following oral candidiasis in the mouse: a model of the carrier state in humans. Oral Microbiol Immunol 8, 313-318.

Mallett, C. P., Van de Verg, L., Collins, H. H. \& Hale, T. L. (1993). Evaluation of Shigella vaccine safety and efficacy in an intranasally challenged mouse model. Vaccine 11, 190-196.

Mallett, C. P., Hale, T. L., Kaminski, R. W., Larsen, T., Orr, N., Cohen, D. \& Lowell, G. H. (1995). Intranasal or intragastric immunisation with proteosome-Shigella lipopolysaccharide vaccines protects against lethal pneumonia in a murine model of Shigella infection. Infect Immun 63, 2382-2386.

Noriega, F. R., Losonsky, G., Lauderbaugh, C., Liao, F. M., Wang, J. Y. \& Levine, M. (1996). Engineered $\triangle g u a B A \Delta v i r G$ Shigella flexneri 2a strain CVD1205: construction, safety, immunogenicity and potential efficacy as a mucosal vaccine. Infect Immun 64, 3055-3061.

Nuget, K. M. \& Onofrio, J. M. (1983). Pulmonary tissue resistance to Candida albicans in normal and immunosuppressed mice. Am Rev Respir Dis 128, 909-914.

Papadimitriou, J. M. \& Ashman, R. B. (1986). The pathogenesis of acute systemic candidiasis in a susceptible inbred mouse strain. $J$ Pathol 150, 257-265.

Pfaller, M. A. (1996). Nosocomial candidiasis: emerging species, reservoirs, and modes of transmission. Clin Infect Dis 22, S89-S94.

Phalipon, A., Kaufmann, M., Michetti, P., Cavaillon, J., Huerre, M., Sansonetti, P. \& Kraehenbuhl, J. P. (1995). Monoclonal immunoglobulin A antibody directed against serotype-specific epitope of Shigella flexneri lipopolysaccharide protects against murine experimental shigellosis. J Exp Med 182, 769-778.

Romani, L., Mencacci, A., Cenci, E., Spaccapelo, R., Mosci, P., Puccetti, P. \& Bistoni, F. (1993). CD4+ subset expression in murine candidiasis. Th responses correlate directly with genetically determined susceptibility or vaccine-induced resistance. J Immunol 150, 925-931.

Romani, L., Cenci, E., Menacci, A., Bistoni, F. \& Puccetti, P. (1995). $T$ helper cell dichotomy to Candida albicans: implications for pathology, therapy, and vaccine design. Immunol Res 14, 148-162.

Roof, M. B. \& Doitchinoff, D. D. (1995). Safety, efficacy and duration of immunity induced in swine by use of an avirulent live Salmonella choleraesuis-containing vaccine. Am J Vet Res 56, 39-44.

Samaranayake, L. P. \& Holmstrop, P. (1989). Oral candidiasis and human immunodeficiency virus infection. J Oral Pathol Med 18, 554-564.

Samonis, G., Dassiou, M. \& Anastassiadou, H. (1994). Antibiotics affecting colonisation of mice by yeasts. J Chemother 6, 50-52.

Sawyer, R. T. (1990). Experimental pulmonary candidiasis. Mycopathologia 109, 99-109.

Sizemore, D. R., Bramstrom, A. A. \& Sadoff, J. C. (1997). Attenuated bacteria as a DNA delivery vehicle for DNA-mediated immunisation. Vaccine 15, 804-807.

Stabel, T. J., Fedorka-Cray, P. J. \& Gray, J. T. (1995). Tumour necrosis factor- $\alpha$ production in swine after oral or respiratory challenge exposure with live Salmonella typhimurium or Salmonella choleraesuis. Am J Vet Res 56, 1012-1018.

van de Verg, L. L., Mallet, C. P., Collins, H. H., Larsen, T., Hammack, C. \& Hale, T. L. (1995). Antibody and cytokine response in a mouse pulmonary model of Shigella flexneri serotype 2a infection. Infect Immun 63, 1947-1954.

Voino-Yasenetsky, M. V. \& Voino-Yasenetsky, M. K. (1962). Experimental pneumonia caused by bacteria of the Shigella group. Acta Morphol Acad Sci Hung 11, 439-454.

Welkos, S. \& O'Brien, A. (1994). Determination of median lethal and infectious doses in animal model systems. In Bacterial Pathogenesis, pp. 29-39. Edited by V. L. Clark \& P. M. Bavoil. London: Academic Press.

Received 26 February 1998; revised 20 April 1998; accepted 4 May 1998. 